\title{
Women in Higher Education: Access, Success, and the Future
}

\author{
Libby V. Morris
}

Published online: 8 April 2011

(C) Springer Science+Business Media, LLC 2011

Several months ago, the Georgia Association for Women in Higher Education asked me to deliver the keynote address for their annual state meeting, with a focus on the "Current Status of Women in Higher Education: Challenges and Strengths to Moving Forward." Over time, I have given time and small donations to various women's advocacy and educational groups; but I must admit I have not been on the forefront of tracking women's achievements and struggles. Developing my own career; mentoring graduate students (and others on campus who needed a listening ear); and tending two boys, a husband, and several family pets kept me busy. So, I found it interesting to do the background research for this talk. Below is a brief summary of my speech and an explanation of why I think the subject raises important questions for authors and readers of Innovative Higher Education.

My talk centered on women's earliest access to higher education, recent gains in enrollment and graduation, and current leadership in executive and administrative positions. We all know that women were excluded from formal education in the earliest years of higher education. The Georgia Female College of Macon, Georgia (now Wesleyan College) and Oberlin College in Ohio led the way in admitting women students in the 1830s, approximately 200 years after Harvard (1636) had enrolled its first class of males in an institution on a frontier that was to become the United States of America. The women's colleges of the Northeast followed soon with the founding of Vassar (1865), Wellesley and Smith (1875), and Bryn Mawr (1884).

The following 100 years saw state colleges and private universities open their doors to women students, and enrollments and graduations increased at an accelerated pace according to the American Council on Education's report about Gender Equity in Higher Education: 2010. Women's share of baccalaureate enrollment and graduation is now close to 60 percent overall, and this percentage has remained consistent since 2000. From no participation to equal participation in a century is actually great progress. However, while the numbers highlight equity, they also conceal the struggle-legal, policy, and personal-that enabled this progress.

L. V. Morris $(\bowtie)$

Institute of Higher Education, University of Georgia, 102 Meigs Hall, Athens, GA 30602-6772, USA

e-mail: lvmorris@uga.edu 
The University of Georgia (UGA), the nation's first chartered public institution of higher education (1785), has participated in every phase of the integration of women into higher education. At UGA, 1961 was a landmark year as Charlayne Hunter-Gault opened the doors of the University for African American women and women of color, following a long legal struggle. This year marked the 50th anniversary of the enrollment of Charlayne Hunter (now Hunter-Gault) and Hamilton Holmes (http://desegregation.uga.edu/). While this anniversary is being recognized at the University by celebrations on 50 days for the 50 years, the beginning was challenging; and this young woman and man endured and overcame institutional and societal barriers to enter and graduate from UGA. Charlayne will return to campus again in March to lead a discussion on her memoir entitled In my place (1993). In spite of the disturbing beginning to her life at UGA, her affection for the University is as great as her many accomplishments in newspapers, magazines, radio, and television. In this outcome, there is a lesson for us and for our students.

Back to the story . . . after climbing the baccalaureate ladder, women's progress in graduate education was a natural next step. The Association of American Colleges and Universities report (Touchton et al. 2008), A measure of equity: Women's progress in higher education, indicates that women earned $45 \%$ of all doctoral degrees in 2005-06. Women earn the majority of master's degrees; but these are largely in fields such as education and nursing, while men continue to earn the majority in engineering and business administration (American Council on Education 2010). The not-so-good news is that women's progress in the computer sciences, mathematics and statistics, and the sciences overall is declining. At every level in the STEM fields, there is a reduced level of participation from the undergraduate to the doctoral levels. Some refer to women's dominance in departments and disciplines traditionally associated with females' occupations as being located in the "academic kitchens" of the university or college, a derogatory term, at best.

In the early twentieth century, women moved into leadership positions in higher education; and the position Dean of Women was created to oversee the growing number of female students, who, of course, would need their own female mentors. To be sure, these early Deans oversaw the social and academic culture for women students; and they surely made a difference between success and failure for many female students. Today, women fill many senior level positions, but still fall short of parity: in the last decade women were $23 \%$ of Presidents, $45 \%$ of senior administrators, $38 \%$ of chief academic officers, $36 \%$ of deans, and $49 \%$ of vice presidents for external affairs (American Council on Education 2010). While many researchers acknowledge women's disproportionate responsibilities for family and maintaining a work/life balance, the gender-based obstacles remain and are seen in lower salaries for women, appointments at lower ranks, slower movement up the career ladder, and less recognition than that given to men.

These issues pose interesting questions for the readers and authors of Innovative Higher Education.

- How will we encourage and reach parity in the leadership of higher education for our daughters and our sisters?

- What case studies would be useful to understand the access and success of women in higher education leadership positions?

- When parity is reached in the leadership of higher education, how will we use our positions to transform the academy?

- If we continue to do more of the same, does parity matter other than on an individual level?

- What has been the role of women's groups in creating opportunity for women, and what are the challenges of networking currently? 
- How can current leaders address the microclimates of higher education, which populates some fields with women and others with men?

I look forward to your innovative responses to bringing about greater access, success, and longevity for women in the academy.

\section{References}

American Council on Education. (2010). Gender equity in higher education: 2010. Washington, DC: Author. Hunter-Gault, C. (1993). In my place. New York: Vintage Books.

Touchton, J., Musil, C. M., \& Campbell, K. P. (2008). A measure of equity: Women's progress in higher education. Washington, DC: Association for American Colleges and Universities. 